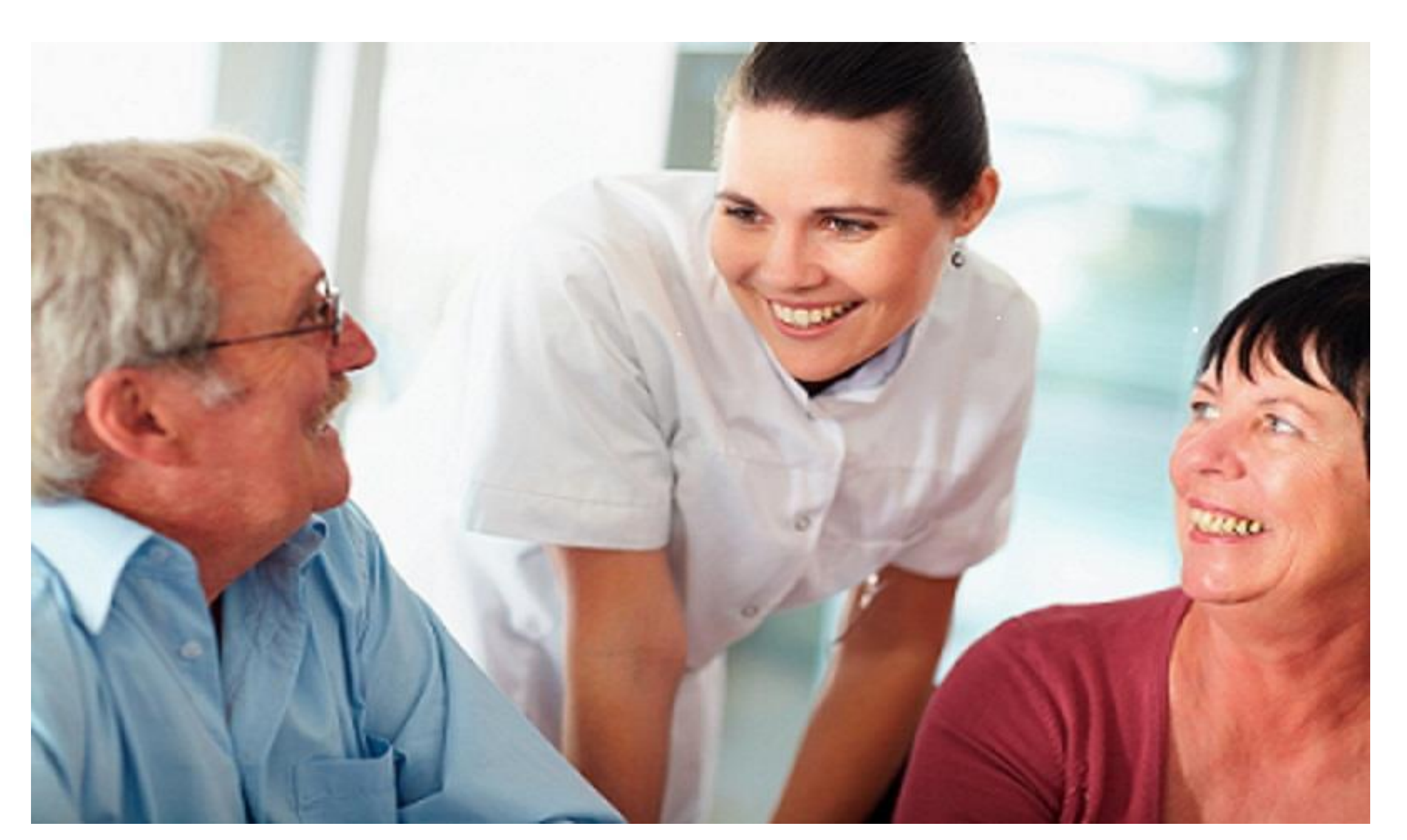

\title{
Contrasting African and Canadian Perspectives: Having Conversations about Sexuality
}

\author{
Margaret Fitch RN PhD ${ }^{1}$, Johanna Maree RN PhD² \\ ${ }^{1}$ Bloomberg Faculty of Nursing, University of Toronto, Toronto, ON, Canada; ${ }^{2}$ Faculty of Health Sciences, University of the Witwatersand, Johannesburg, South Africa
}

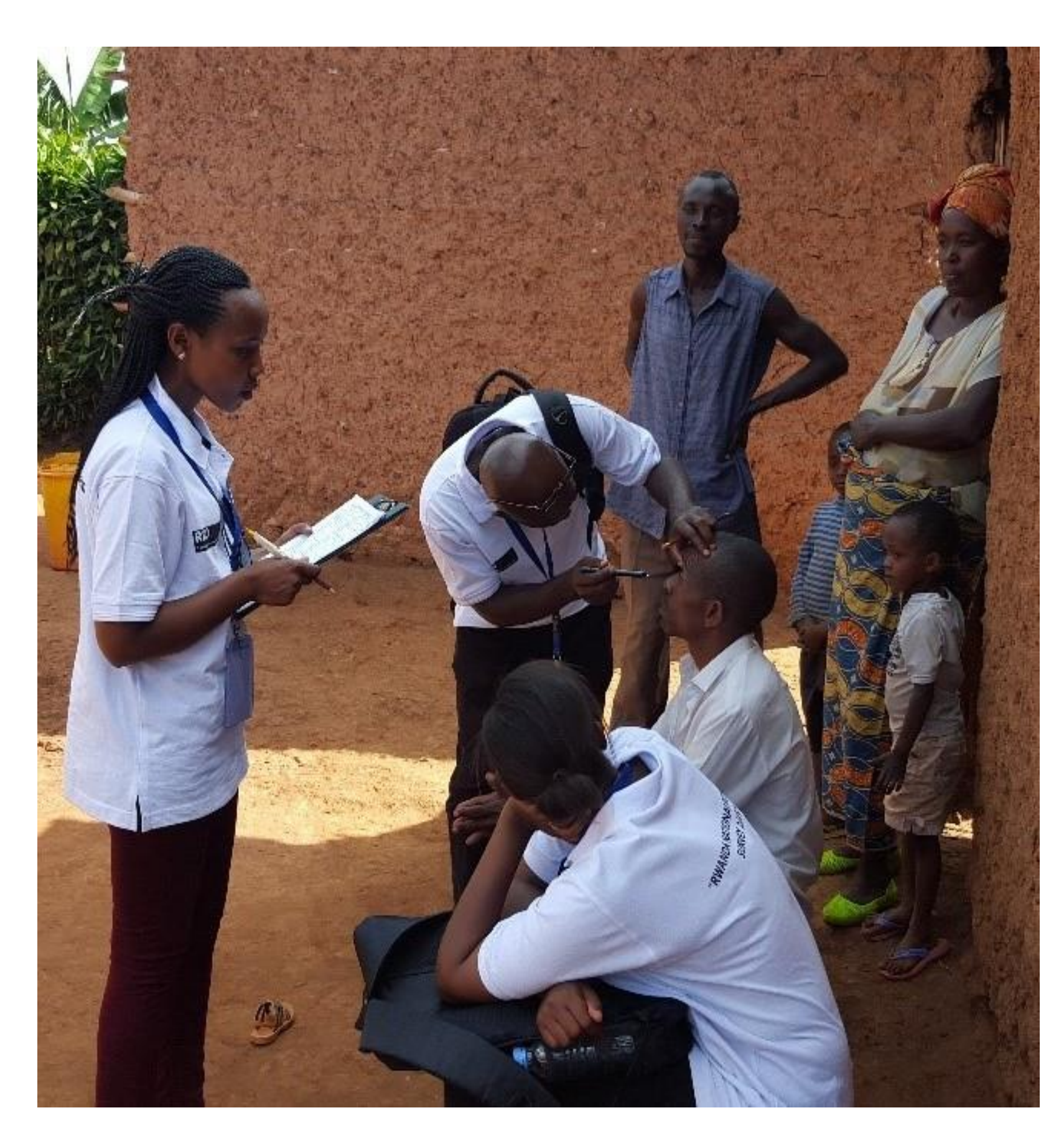

\section{INTRODUCTION} of life as there are multiple physical, emotional, psychosocial, spiritual, and practical changes [1]. In particular, body changes and alterations in bodily functions can influence body image, self-esteem, fertility, and sexual functioning. In short, one's sexuality can be compromised.

Sexuality is an important aspect of quality of life and a central aspect of being human $[2,3]$. Unresolved issues regarding sexuality stemming from cancer treatment can contribute to heightened emotional distress [4]. Whole person-care means paying attention to all aspects of an person, including issues of sexuality [5].

Studies have documented that sexuality needs frequently remain unmet their visits with physicians and nurses $[7,8]$. There is increasing evidence that conversations about these specific consequences are not happening often between cancer patients and health care providers, especially in busy ambulatory settings.

\section{PURPOSE}

This work was undertaken to gain an increased understanding about the dialogue between cancer care professionals and cancer patients regarding the topic of sexuality. It was anticipated the effort would allow identification of barriers that exist, which limit dialogue, and insight regarding how to overcome such barriers in a busy clinical setting. Focal points in Canada and Zimbabwe allowed the topic to be explored in two distinct geographical situations.

\section{METHODS}

Qualitative approaches were utilized to complete this exploratory work.

In Canada

Individual in-depth semi-structured interviews were held with health care providers. Interviews were audiotaped and transcribed verbatim. A content analysis of verbatim transcripts was completed to identify salient themes.

In Zimbabwe

Small group focus sessions were held health care providers during an introductory course on cancer care. Written notes were maintained outlining the small group discussions and verbal reports. A content analysis of the notes was completed and salient themes identified.

DEMOGRAPHICS

\begin{tabular}{ll} 
& Health Care Providers in Canada $(n=34)$ \\
\hline Oncologists & 11 \\
Nurses/Radiation Therapists & $12 / 5$ \\
Social Workers & 6
\end{tabular}

$\begin{array}{lc} & \text { Health Care Providers in Africa }(\mathbf{N}=27) \\ \text { Nurses } & 22 \\ \text { Technologists/Registry } & 5\end{array}$

\section{RESULTS}

There was a surprising amount of similarity in the perspectives held by the individuals. All acknowledged sexuality was an important dimension of being human and were aware of the potential for cancer treatment to have an impact upon sexuality.

All shared the perspective that having a conversation about sexuality was difficult for both health care professionals and for patients. However, it was clear that individual practices concerning conversations about sexuality varied considerably and were closely linked with individuals' personal comfort, philosophy of care, perception of role, and preparation concerning the topic area (including education, skill training, and confidence). No one described policy or explicitly stated expectations about how this topic was to be handled in the clinical setting. The only consistency in practice regarding conversations about sexuality occurred within the informed consent processes for cancer treatment.

A major difference in the barriers to having conversations about sexuality between the two countries concerned the influence of culture and tradition. African participants placed considerable emphasis on the influences of traditional practices and shared public perception that talking about sexual topics was a taboo. Fear of being shamed and stigmatized was a strong influence on patients; they would opt to remain silent in light of this fear rather than talk about needing assistance with sexual concerns.

\section{CONCLUSION}

The findings support the need to clarify role expectations for cancer nurses, as well s other members of the cancer care team, about patient care regarding sexuality, and the provision of education for the staff to support the expected role.
Cancer treatment can have a significant impact on an individual's quality [6] and patients report their concerns about sexuality as not always addressed during

PERSPECTIVES AND QUOTES

\begin{tabular}{|c|c|}
\hline Themes & Canadian Participants \\
\hline $\begin{array}{l}\text { The extent of the impact cancer } \\
\text { and cancer treatment can have } \\
\text { on a person's sexuality varies by } \\
\text { the site of the cancer. }\end{array}$ & $\begin{array}{l}\text { "If they [prostate patients] don't } \\
\text { bring it up, then I do because the } \\
\text { treatment can affect sexuality in all } \\
\text { of the patients." } \\
\text { "I never raise it with them [CNS } \\
\text { patients] as they are so impaired, I } \\
\text { just don't." } \\
\text { I raise the topic with all my cervical } \\
\text { patients but never with my breast } \\
\text { patients because they only get } \\
\text { radiation." }\end{array}$ \\
\hline $\begin{array}{l}\text { Sexuality is not perceived as a } \\
\text { priority for cancer patients, } \\
\text { especially during diagnosis and } \\
\text { treatment. }\end{array}$ & $\begin{array}{l}\text { "I think patients want to treat the } \\
\text { cancer first and foremost." } \\
\text { "I would not bring up anything } \\
\text { associated with sexuality to head and } \\
\text { neck cancer patients. They are just } \\
\text { too miserable to even think of sex. If } \\
\text { you can't eat, you can't swallow, you } \\
\text { can barely breather, sex is the last } \\
\text { thing on your mind." }\end{array}$ \\
\hline $\begin{array}{l}\text { If sexuality is going to be a } \\
\text { concern for cancer patients it } \\
\text { will occur after treatment is } \\
\text { finished. }\end{array}$ & $\begin{array}{l}\text { "it's not an issue with patients on } \\
\text { treatment; it is more an issue before } \\
\text { and after treatment." }\end{array}$ \\
\hline $\begin{array}{l}\text { Conversations about sexuality } \\
\text { occur most often in the context } \\
\text { of informed consent discussion } \\
\text { prior to surgery or treatment or } \\
\text { if the patient raises a specific } \\
\text { question }\end{array}$ & $\begin{array}{l}\text { "I speak to the young men with testes } \\
\text { cancer about sperm banking and } \\
\text { fertility, but rarely initiate any } \\
\text { conversations about the patient's } \\
\text { situation otherwise." }\end{array}$ \\
\hline $\begin{array}{l}\text { If cancer patients have } \\
\text { difficulties or concerns about } \\
\text { sexuality, they will ask questions } \\
\text { or tell the health professional. }\end{array}$ & $\begin{array}{l}\text { "I think patients will raise any } \\
\text { concerns they have." } \\
\text { "I wait until they raise the concerns." }\end{array}$ \\
\hline
\end{tabular}

\section{African Participants Nurses see the impact of treatment sexuality. \\ It is a cultural taboo to talk about it. Some cultures and religions do not allow talking about sexuality. \\ The doctor/nurse is in a hurry to see other patients so the issue of sexuality to him or her is not big business, rather would like to concentrate more on the disease than issues like sexuality. \\ Patients feel embarrassed expressing anything about sexuality and feel shame discussing their sexual problems; they fear being marked and stigmatized. \\ Before some surgeries there is sharing of information. But nurses are so busy there is no time and conducive environment to give patients the opportunity to talk; most hospital settings are crowded with patients. No time and no privacy. And patients have many things to do when they come to the hospital like lab tests and radiology. \\ Patients do not trust nurses as they feel the nurses might tell others bout them or tell their families, so they keep it all private. They are not willing to share their inner life.}

\section{Perspectives about the
conversations}

Canadian Participants

Why cancer patients find it difficult to talk about sexual concerns

The following factors were named:

age, culture, private/personal topic, embarrassment, gender, language, being overwhelmed from the cancer, being overwhelmed from the trust and rapport with the professional, time, sexual orientatio relationship between partners, perceived role of professional

Why health care professionals find it difficult to talk about sexual concerns

The following factors were named:

Time, patient load, clinic flow, priority efforts are on disease care personal comfort, lack of training and experience, privacy in the clinic, perceived role, incentive

Suggestions for managing conversations about sexual matters with cancer patients

Set a standard of care that all patients are informed about the patients are informed about the impact of car

sexuality.

Ensure information is about side effects and the impact on various aspects of sexuality. Basic assessment is patients ought to include questions about sexual concerns and whether the person wants help with them. Staff ought to check in with patients on a regular basis about whether sexual concerns have changed. Include educational resources about sexuality for patients in the clinics. Hold staff accountable for focusing on sexuality as a routine focusing on sexuality as a routine part of their Offer staff training programs on interventions)

Develop a list of resources so that referrals can be made appropriately.
African Participants

The following factors were emphasized:

Culture/tradition/taboo

Age/gender

Stigmatization/fear

Embarrassment/mistrust

Religion

Private personal topic

The following factors wer emphasized:

Culture/tradition

lack of knowledge and skill regarding the topic

Time/workload

Lack of privacy

Have someone from same cultural group talk with patien

Put posters on the wall of clinic

Have someone who is same gender and age talk with patient

Hold classes with same age groups and one gender

Emphasize health in conversations

Use an education approach

Offer staff training programs sexuality (assessment and 